\title{
Novel-Type Charge-Transfer Complex Formation between Indoxyl Sulfate and Anthraquinonesulfonate Ions in an Aqueous Polyelectrolyte Solution
}

\author{
Yoshiya Kawabata, ${ }^{\dagger}$ Tomoyuki ItAYA, ${ }^{*}$ Kazuyoshi UedA, ${ }^{* *}$ Hiroshi OchiaI, ${ }^{* * *}$ \\ Yuriko AOKI, ${ }^{* * * *}$ and Akira IMAMURA ${ }^{* * * * *}$ \\ Department of Applied Quantum Physics and Nuclear Engineering, \\ Graduate School of Engineering, Kyushu University, Fukuoka 812-8581, Japan \\ *Laboratory of Chemistry, Department of General Education, Nagano National College of Technology, \\ Nagano 381-8550, Japan \\ ${ }^{* *}$ Division of Mechanical Engineering and Material Science, Graduate School of Engineering, \\ Yokohama National University, Yokohama 240-8501, Japan \\ *** Department of Science Education, Faculty of Education, Hiroshima University, \\ Higashi-Hiroshima 739-8524, Japan \\ **** Department of Chemistry, Graduate School of Science, Hiroshima University, \\ Higashi-Hiroshima 739-8524, Japan \\ ***** Department of General Education, Faculty of Engineering, Hiroshima Kokusai Gakuin University, \\ Hiroshima 739-0321, Japan
}

(Received July 29, 2002; Accepted November 1, 2002)

\begin{abstract}
Charge-transfer (CT) complexation between indoxyl sulfate (3-indolyl hydrogen sulfate) (InS : electron donor) and 9,10-anthraquinone-2-sulfonate (2-AQS ${ }^{-}$: electron acceptor) around cationic polymers (poly(allylammonium chloride) $\left(\mathrm{PAAH}^{+} \mathrm{Cl}^{-}\right)$and poly $\left(1,1\right.$-dimethylpiperidinium-3,5-diylmethylene chloride) $\left(\mathrm{PDPD}^{+} \mathrm{Cl}^{-}\right)$) were studied by absorption and fluorescence spectroscopies and molecular orbital calculation. New broad UV bands corresponding to CT complexation between $\mathrm{InS}^{-}$and $2-\mathrm{AQS}^{-}$at low concentration $\left(\sim 10^{-4} \mathrm{M}\right)$ was observed when these polymers were present in the systems. A continuous variation method for the $\mathrm{InS}^{-} / 2-\mathrm{AQS}^{-} /$polymer systems showed that a novel type $\left(\mathrm{InS}^{-}: 2-\mathrm{AQS}^{-}=2: 1\right) \mathrm{CT}$ complex preferentially formed in the vicinity of these polyions. Stoichiometric ratio of the present $\mathrm{CT}$ complex was not affected by the structure and charge density of polyelectrolytes.

KEY WORDS Charge-Transfer / Polyelectrolyte / Counterion Binding / Heterocyclic Compound /
\end{abstract}

Hydrophobic, stacking interactions between organic compounds are important intermolecular interactions in the field of host-guest chemistry. In addition, chargetransfer (CT) interaction between electron-donative (donor) and electron-acceptive (acceptor) molecules is of interest in connection with studies for model systems of enzyme-coenzyme, occurrence of functionality in biological systems. The elucidation of CT interactions, which correlating with polymers, is expected to contribute to utilizing polymer catalysts, medical and pharmaceutical polymers. The CT complexations in organic media have been already investigated for low molecular-weight donor/acceptor systems, or electrondonative polymer/low molecular-weight acceptor systems in detail. ${ }^{1-4}$ However, few studies have been reported on the CT interaction in aqueous media, ${ }^{5}$ due to low solubility of organic compounds in aqueous solution.

Polyelectrolytes, which have many ionizable groups fixed on their side chains or polymer backbone, dissociate into polyions and their counterions in aque-

\footnotetext{
${ }^{\dagger}$ To whom correspondence should be addressed.
}

ous solution. Charged groups on the polyion form a strong electrostatic field and attract a number of oppositely charged ions by an electrostatic interaction. This interaction is well known as counterion binding and/or condensation effect, which is one of the characteristic properties of polyelectrolyte solutions. $^{6-8}$ We have reported that by utilizing the counterion binding, the CT complexes form between donor and acceptor counterions in aqueous solution in the presence of polyelectrolytes. ${ }^{9-13}$ The donor counterions used in the previous studies were 9,10dimethoxyanthracene-2-sulfonate, 1-pyrenesulfonate, anthracene-2-sulfonate, and the acceptor counterion was 9,10-anthraquinone-2-sulfonate $\left(2-\mathrm{AQS}^{-}\right)$. The polyelectrolytes used were poly(allylammonium chloride) $\left(\mathrm{PAAH}^{+} \mathrm{Cl}^{-}\right)$and poly(1,1-dimethylpiperidinium3,5-diylmethylene chloride) $\left(\mathrm{PDPD}^{+} \mathrm{Cl}^{-}\right) \cdot{ }^{9-13}$ As these CT complexations occur in the electrostatic field created by polyelectrolytes. Therefore, the CT complexations are affected not only by the properties and the structure of donor and acceptor counterions, but also the charge density of polyelectrolytes. From these pre- 


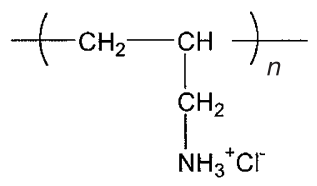

$\mathrm{PAAH}^{+} \mathrm{Cl}^{-}$

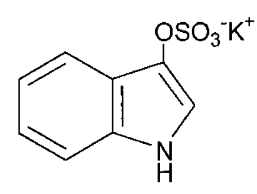

$\mathrm{K}^{+} \operatorname{lnS}$

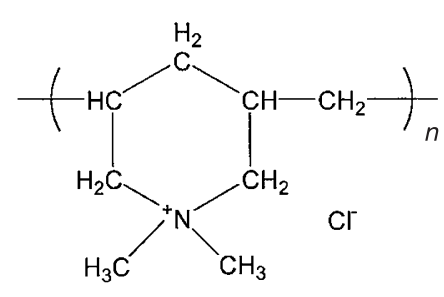

$\mathrm{PDPD}^{+} \mathrm{Cl}$

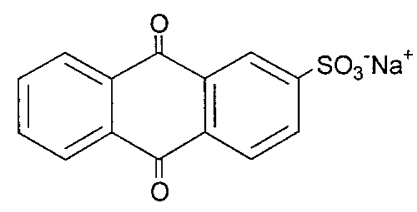

$\mathrm{Na}^{+} 2-\mathrm{AQS}$
Figure 1. Chemical structures of $\mathrm{PAAH}^{+} \mathrm{Cl}^{-}, \mathrm{PDPD}^{+} \mathrm{Cl}^{-}$, $\mathrm{K}^{+} \mathrm{InS}^{-}$, and $\mathrm{Na}^{+} 2-\mathrm{AQS}^{-}$.

vious studies, it has been found that not only 1:1-type but also 1:2-type CT complexes were formed in the above systems. However, there still remains a possibility to discover new types of CT complexes, if we will investigate different types combinations of counterions and polyelectrolytes. These results indicate that the presence of polyelectrolyte may give rise to a novel CT complex, however, the details are not clear.

As a continuation of a series of research, we investigated the CT complexation of $\mathrm{InS}^{-}$(a heterocyclic compound) with 2-AQS ${ }^{-}$in the polymer solutions of $\mathrm{PAAH}^{+} \mathrm{Cl}^{-}$and $\mathrm{PDPD}^{+} \mathrm{Cl}^{-}$. Owing to the heterocyclic property of $\mathrm{InS}^{-}$, a novel CT complex would be expected to produce. As a result, we found the formation of a new type CT complex with 2:1 (InS $\left.\mathrm{I}^{-}: 2-\mathrm{AQS}^{-}\right)$ stoichiometric ratio, that is caused by the effect of the heterocyclic part of $\mathrm{InS}^{-}$on the CT complexation with 2-AQS ${ }^{-}$around the polyions.

\section{EXPERIMENTAL}

\section{Materials}

Poly(allylammonium chloride) $\left(\mathrm{PAAH}^{+} \mathrm{Cl}^{-}\right)$was kindly donated by Nitto Boseki Co. Ltd., and poly(1,1dimethylpiperidinium-3,5-diylmethylene chloride) (P$\mathrm{DPD}^{+} \mathrm{Cl}^{-}$) was purchased from Aldrich Chemical Co. Inc., respectively. These polymers were purified by reprepititation described previously. ${ }^{10,14}$ Weight-average molecular weights of the polymers were determined by the light scattering measurement to be $1.0 \times 10^{5}$ for both polymers in $0.2 \mathrm{M} \mathrm{NaCl}$ solution, and their degree of polymerization were roughly $1.1 \times 10^{3}$, and
$6.2 \times 10^{2}$, respectively.

Potassium indoxyl sulfate (3-indolyl hydrogen sulfate) $\left(\mathrm{K}^{+} \mathrm{InS}^{-}\right)$and sodium 9,10-anthaquinone-2-sulfonate $\left(\mathrm{Na}^{+} 2-\mathrm{AQS}^{-}\right)$of analytical reagent grade were purchased from Fluka Bio Chemika, Tokyo Kasei Co. Ltd., respectively. Since the spectra for the solutions of purified samples were identical with those for the raw samples, these samples were used without further purification. Chemical structures of $\mathrm{PAAH}^{+}, \mathrm{PDPD}^{+}$, $\mathrm{InS}^{-}$, and 2-AQS ${ }^{-}$are shown in Figure 1.

Deionized and distilled water was used as a solvent. In order to prevent the formation of the precipitation, sample solutions for the absorption spectroscopic measurements were first prepared by adding known amounts of the polymers in stock solution to the water to empty vials, and then followed by poured known amounts of the aromatic salts solution to the vials. Concentrations were expressed as the residue molar concentration (M) for the polymers and as molar concentration (M) for counterions $\left(1 \mathrm{M}=1 \mathrm{~mol} \mathrm{dm}^{-3}\right)$.

\section{Measurements}

The absorption spectra were recorded at $25^{\circ} \mathrm{C}$ on a Shimadzu 265FW spectrophotometer equipped with a thermostated cell compartment. Quartz cells with the path length of $10 \mathrm{~mm}$ and $50 \mathrm{~mm}$ were used.

The steady-state fluorescence spectra of $\mathrm{InS}^{-}$were measured on a JASCO FP-777 fluorescence spectrometer at room temperature. Excitation of $\mathrm{InS}^{-}$was done at $290 \mathrm{~nm}$.

Molecular-orbital calculation of $\mathrm{InS}^{-}$was performed using a semi-empirical molecular-orbital calculation program of MOPAC ${ }^{15}$ ver. 6.01 with the $\mathrm{PM}^{16}$ method. The chemical structures for $\mathrm{InS}^{-}$and 2-AQS ${ }^{-}$were obtained by using fully optimized the structures with the PM3 Hamiltonian.

\section{RESULTS AND DISCUSSION}

First, we discuss the interaction between $\mathrm{InS}^{-}$and $\mathrm{PAAH}^{+}$and the association behavior of $\mathrm{InS}^{-}$around $\mathrm{PAAH}^{+} \mathrm{Cl}^{-}$before mentioning $\mathrm{CT}$ complexation between $\mathrm{InS}^{-}$and $2-\mathrm{AQS}^{-}$. Figure 2 shows the absorption (a) and fluorescence (b) spectra of $\mathrm{K}^{+} \mathrm{InS}^{-}$ in aqueous solution in the presence and absence of $\mathrm{PAAH}^{+} \mathrm{Cl}^{-}$. The absorption spectra of $\mathrm{InS}^{-}$did not exhibit any spectral change by the addition of $\mathrm{PAAH}^{+} \mathrm{Cl}^{-}$, i.e., hypochromism, red or blue shifts and isosbestic points which indicate an association behavior. In the fluorescence spectra, the addition of $\mathrm{PAAH}^{+} \mathrm{Cl}^{-}$led to the decrease in the emission intensity of $\mathrm{InS}^{-}$, indicating of the concentration quenching of the emission of $\mathrm{InS}^{-}$due to the coun- 

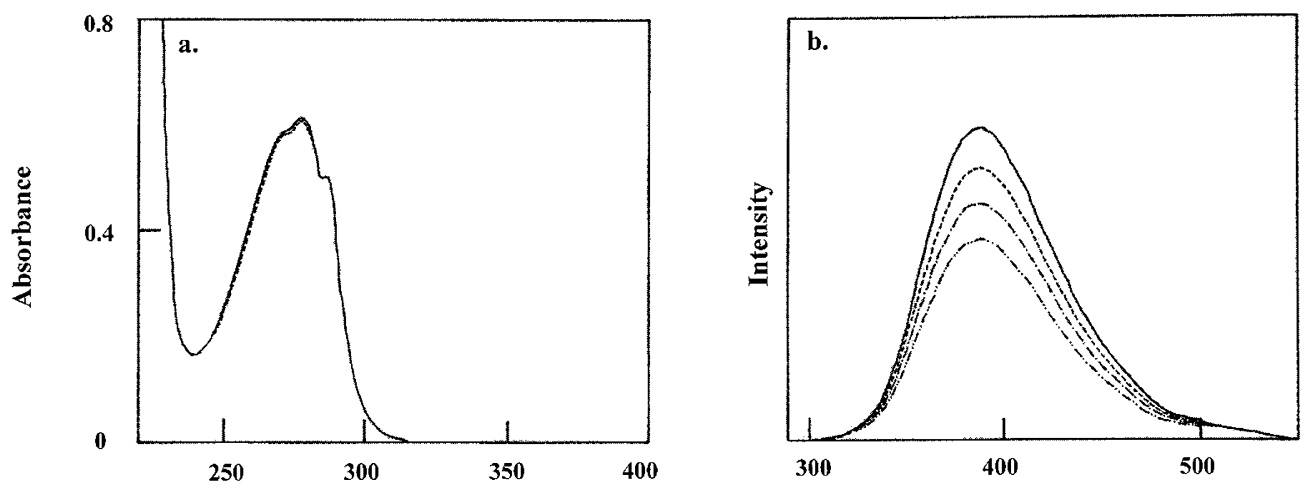

Wavelength / nm

Figure 2. Absorption spectra (a) and fluorescence spectra (b) of aqueous solutions of $\mathrm{K}^{+} \operatorname{InS}^{-}\left(1.1 \times 10^{-4} \mathrm{M}\right)$ in the presence and absence of $\mathrm{PAAH}^{+} \mathrm{Cl}^{-}$. Cells with a light path of $10 \mathrm{~mm}$ were used. The fluorescence spectra were obtained by excitation at $290 \mathrm{~nm}$. [PAAH $\left.\mathrm{Pl}^{-}\right]=$ $0 \mathrm{M}(-), 5.5 \times 10^{-5} \mathrm{M}(---), 1.1 \times 10^{-4} \mathrm{M}(-\cdot-)$, and $2.2 \times 10^{-4} \mathrm{M}(-\cdot-)$.

terion binding to $\mathrm{PAAH}^{+}$. From these results (Figures $2 \mathrm{a}$ and $\mathrm{b}$ ), it can be concluded that an association of $\mathrm{InS}^{-}$hardly occurs in spite of the counterion binding of $\mathrm{InS}^{-}$to $\mathrm{PAAH}^{+}$. Generally speaking, it is well known that an intermolecular plane-to-plane distance between aromatic rings is $c a .3 .3-3.5 \AA$ in stacking interaction. ${ }^{17}$ An ionic site of $\mathrm{InS}^{-}\left(-\mathrm{OSO}_{3}{ }^{-}\right)$ has a free rotation due to a single bond between indolyl ring and $\mathrm{SO}_{3}{ }^{-}$part. From a molecular orbital calculation, it is found that the ionic site of $\mathrm{InS}^{-}$($\mathrm{OSO}_{3}{ }^{-}$) is not coplanar to indolyl ring, suggesting the distance between $\mathrm{InS}^{-}$ions bound to the polyion enlarges. Thus, it seems that $\mathrm{InS}^{-}$molecules bound to the polyion through the counterion binding cannot associate with each other via stacking (plane-to-plane) interaction.

We next investigated the CT complexation between $\mathrm{InS}^{-}$and $2-\mathrm{AQS}^{-}$in the presence and absence of both $\mathrm{PAAH}^{+} \mathrm{Cl}^{-}$and $\mathrm{PDPD}^{+} \mathrm{Cl}^{-}$. When $\mathrm{K}^{+} \mathrm{InS}^{-}$ $\left(1 \times 10^{-3} \mathrm{M}\right.$; colorless $)$ and $\mathrm{Na}^{+} 2-\mathrm{AQS}^{-}\left(1 \times 10^{-3} \mathrm{M}\right.$; colorless) were mixed, a color change of the solution from colorless to pale yellow was observed. However, such a color change was not detected in the condition of $\left[\mathrm{InS}^{-}\right]=\left[2-\mathrm{AQS}^{-}\right]=1 \times 10^{-4} \mathrm{M}$. On the other hand, the addition of the polymers to the solution containing both $\mathrm{K}^{+} \mathrm{InS}^{-}\left(1 \times 10^{-4} \mathrm{M}\right)$ and $\mathrm{Na}^{+} 2-\mathrm{AQS}^{-}$ $\left(1 \times 10^{-4} \mathrm{M}\right)$ produced a similar color change of the solution again. These suggested that CT complexations occur between $\mathrm{InS}^{-}$and 2-AQS ${ }^{-}$. Especially, polyelectrolytes seem to play an important role to produce a special environment for CT complexation in a condition for low concentration of these aromatic counterions. Figure 3 shows the absorption spectra of $\mathrm{K}^{+} \mathrm{InS}^{-}$/ $\mathrm{PAAH}^{+} \mathrm{Cl}^{-}, \mathrm{Na}^{+} 2-\mathrm{AQS}^{-} / \mathrm{PAAH}^{+} \mathrm{Cl}^{-}$, and $\mathrm{K}^{+} \mathrm{InS}^{-} /$ $\mathrm{Na}^{+} 2-\mathrm{AQS}^{-} / \mathrm{PAAH}^{+} \mathrm{Cl}^{-}$systems. In the $\mathrm{K}^{+} \mathrm{InS}^{-} /$ $\mathrm{Na}^{+} 2-\mathrm{AQS}^{-} / \mathrm{PAAH}^{+} \mathrm{Cl}^{-}$system, a new broad $\mathrm{CT}$ band

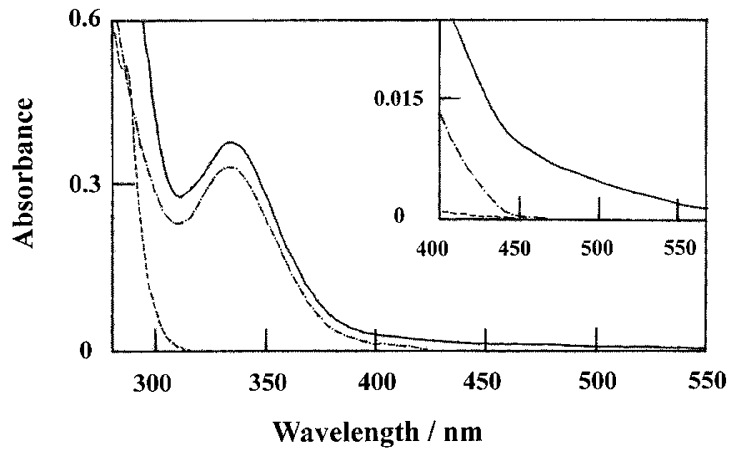

Figure 3. Absorption spectra of $\mathrm{K}^{+} \mathrm{InS}^{-} / \mathrm{PAAH}^{+} \mathrm{Cl}^{-}(---)$, $\mathrm{Na}^{+} 2-\mathrm{AQS}^{-} / \mathrm{PAAH}^{+} \mathrm{Cl}^{-}(-\cdot-)$, and $\mathrm{K}^{+} \mathrm{InS}^{-} / \mathrm{Na}^{+} 2-\mathrm{AQS}^{-} / \mathrm{PAAH}^{+} \mathrm{Cl}^{-}$ (-) systems. Cells with a light path of $10 \mathrm{~mm}$ were used. $\left[\mathrm{K}^{+} \mathrm{In}-\right.$ $\left.\mathrm{S}^{-}\right]=1.1 \times 10^{-4} \mathrm{M},\left[\mathrm{Na}^{+} 2-\mathrm{AQS}^{-}\right]=1.1 \times 10^{-4} \mathrm{M},\left[\mathrm{PAAH}^{+} \mathrm{Cl}^{-}\right]=$ $4.4 \times 10^{-4} \mathrm{M}$.

appeared which was attributed to the occurrence of the CT complexation between $\mathrm{InS}^{-}$and 2-AQS ${ }^{-}$. A wavelength of absorption maximum of a new band was determined from the difference spectra that obtained by subtracting the spectra of $\mathrm{K}^{+} \mathrm{InS}^{-} / \mathrm{PAAH}^{+} \mathrm{Cl}^{-}$and $\mathrm{Na}^{+} 2-\mathrm{AQS}^{-} / \mathrm{PAAH}^{+} \mathrm{Cl}^{-}$solutions from the spectra of $\mathrm{K}^{+} \mathrm{InS}^{-} / \mathrm{Na}^{+} 2-\mathrm{AQS}^{-} / \mathrm{PAAH}^{+} \mathrm{Cl}^{-}$solution. To obtain accurate difference spectra, the rates of binding of these counterions to the polyion and the association constant of the CT complex should be considered. However, this constant is difficult to obtain in this system because the CT complex formed only when donor and acceptor molecules were closely bound to the polyion moiety. Exact association constant could not be obtained because the intensity of spectra was too low when the concentrations of these counterions were lowered. When the concentrations were raised, the polymer precipitated. Moreover, the Benesi-Hildebrand equation, which is often used to determine association constants of molecular complexes, is applicable to 1:1-type complex formations, whereas, that equation is inapplicable 
to other type complex formations. So, the wavelength at a maximum that obtained by the above-mentioned method should be considered as an approximation. The wavelength thus obtained was $c a .410 \mathrm{~nm}$.

To determine stoichiometries of the CT complexes formed in the presence and absence of the polyions, a continuous variation method ${ }^{18}$ was used for the intensity of the CT band at the wavelength of $450 \mathrm{~nm}$ (Fig-

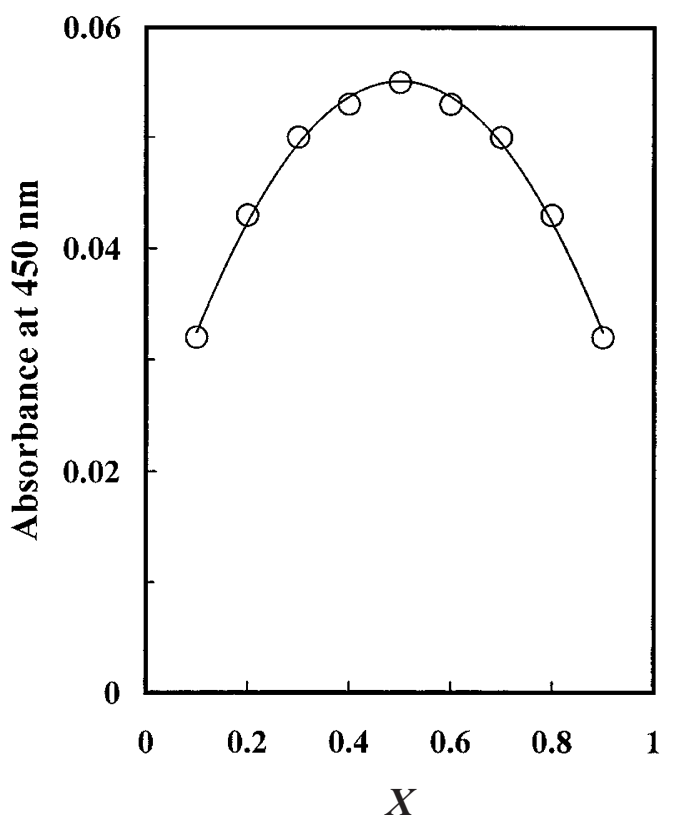

Figure 4. Continuous variation plot for CT complexation between $\mathrm{InS}^{-}$and $2-\mathrm{AQS}^{-}$in pure water. Cells with a light path of $10 \mathrm{~mm}$ were used. $\left[\mathrm{K}^{+} \mathrm{InS}^{-}\right]+\left[\mathrm{Na}^{+} 2-\mathrm{AQS}^{-}\right]=2.2 \times 10^{-3} . X=$ $\left[\mathrm{K}^{+} \mathrm{InS}^{-}\right] /\left\{\left[\mathrm{K}^{+} \mathrm{InS}^{-}\right]+\left[\mathrm{Na}^{+} 2-\mathrm{AQS}^{-}\right]\right\}$.

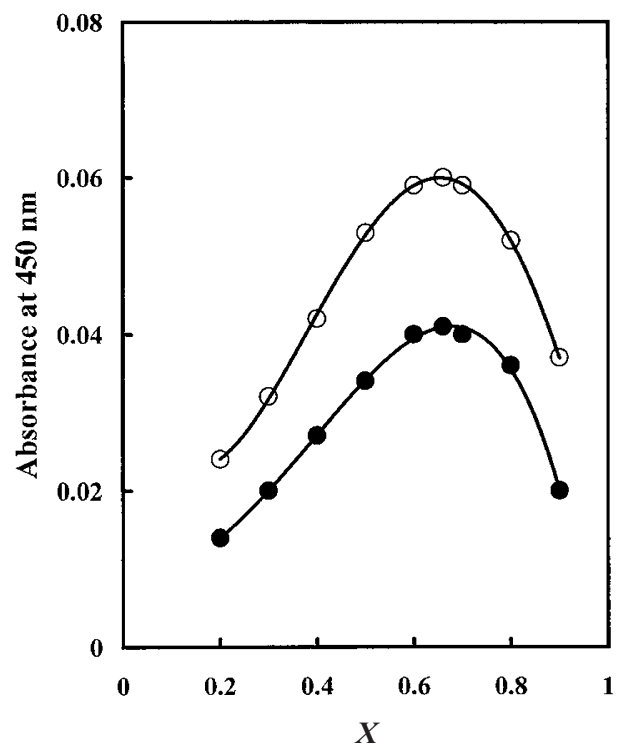

Figure 5. Continuous variation plot for CT complexation between $\mathrm{InS}^{-}$and $2-\mathrm{AQS}^{-}$in aqueous solution of $3.3 \times 10^{-4} \mathrm{M}$ $\mathrm{PAAH}^{+} \mathrm{Cl}^{-}\left(-\mathrm{O}^{-}\right)$and $4.4 \times 10^{-4} \mathrm{M} \mathrm{PDPD}^{+} \mathrm{Cl}^{-}\left(-\mathbf{O}^{-}\right)$. Cells with a light path of $50 \mathrm{~mm}$ were used. $\left[\mathrm{K}^{+} \mathrm{InS}^{-}\right]+\left[\mathrm{Na}^{+} 2-\mathrm{AQS}^{-}\right]=$ $2.2 \times 10^{-4}$ M. $X=\left[\mathrm{K}^{+} \mathrm{InS}^{-}\right] /\left\{\left[\mathrm{K}^{+} \mathrm{InS}^{-}\right]+\left[\mathrm{Na}^{+} 2-\mathrm{AQS}^{-}\right]\right\}$. ures 4 and 5). In the absence of the polyions (Figure 4), the total concentration of the counterions $\left(\left[\mathrm{K}^{+} \mathrm{InS}^{-}\right]+\right.$ $\left.\left[\mathrm{Na}^{+} 2-\mathrm{AQS}^{-}\right]\right)$was adjusted to $2.2 \times 10^{-3} \mathrm{M}$ for all points measured. In this system, a maximum appeared at $X=0.5$, where $X=\left[\mathrm{K}^{+} \mathrm{InS}^{-}\right] /\left(\left[\mathrm{K}^{+} \mathrm{InS}^{-}\right]+\left[\mathrm{Na}^{+} 2-\right.\right.$ $\left.\mathrm{AQS}^{-}\right]$), suggesting that $\mathrm{InS}^{-}$and $2-\mathrm{AQS}^{-}$form a $1: 1-$ type CT complex in pure water. Since both $\mathrm{InS}^{-}$and 2-AQS ${ }^{-}$have a charged group $\left(-\mathrm{OSO}_{3}{ }^{-},-\mathrm{SO}_{3}{ }^{-}\right)$, the electrostatic repulsion between their charged groups may disturb the complex formation more than 1:1 type complex. On the other hand, Figure 5 shows the result for the presence of the polyions. The total concentration of the counterions $\left(2.2 \times 10^{-4} \mathrm{M}\right)$ and the concentration of both $\mathrm{PAAH}^{+} \mathrm{Cl}^{-}\left(3.3 \times 10^{-4} \mathrm{M}\right)$ and $\mathrm{PDPD}^{+} \mathrm{Cl}^{-}\left(4.4 \times 10^{-4} \mathrm{M}\right)$ were adjusted, respectively. As shown in Figure 5, the maxima appeared $X=0.67$ in both $\mathrm{PAAH}^{+} \mathrm{Cl}^{-}$and $\mathrm{PDPD}^{+} \mathrm{Cl}^{-}$systems, which indicated that 2:1 ( $\left.\mathrm{InS}^{-}: 2-\mathrm{AQS}^{-}\right)$-type CT complex was preferentially formed. This indicates that the different structure of CT complex appeared in the presence of the polyelectrolytes. When the 2:1 complex is formed, three or above oppositely charged groups are required to screen out the repulsion between $-\mathrm{OSO}_{3}{ }^{-}$group of $\mathrm{InS}^{-}$and $-\mathrm{SO}_{3}{ }^{-}$group of $2-\mathrm{AQS}^{-}$. Polyelectrolytes satisfy that condition because they have many ionizable groups fixed on their side chain, and create a strong electrostatic field which is suitable for this CT complex formation. The types of CT complexes with 2-AQS (acceptor) obtained in the previous and presence studies are summarized in Table I with the present result. It can be seen that the 2:1 CT complex is the new type. Especially, it is interesting that 2:1 ( $\left.\mathrm{InS}^{-}: 2-\mathrm{AQS}^{-}\right)$-type CT complex was formed in spite of the association of 2-AQS ${ }^{-}$'s was observed in the presence of $\mathrm{PAAH}^{+}$.

CT interaction generally occurs through partial electron transfer from the highest occupied molecular orbital (HOMO) of donor molecule to lowest unoccupied molecular orbital (LUMO) of acceptor molecule. ${ }^{19,20}$ By considering the overlap of electron orbitals between $\mathrm{HOMO}$ of $\mathrm{InS}^{-}$and LUMO of 2-AQS ${ }^{-}$, we tried to elucidate plausible structure of the CT complex. In the

Table I. Types (donor: acceptor) of Charge-Transfer complexes with 2- $\mathrm{AQS}^{-}$(acceptor)

\begin{tabular}{lcc}
\hline & PAAH $^{+} \mathrm{Cl}^{-}$ & $\mathrm{PDPD}^{+} \mathrm{Cl}^{-}$ \\
\hline DMACS $^{-\mathrm{a}}$ & $1: 2$ & $1: 1$ \\
$\mathrm{ACS}^{-\mathrm{b}}$ & $1: 2$ & $1: 1$ \\
$\mathrm{PyS}^{-\mathrm{b}, \mathrm{c}}$ & $1: 1$ & $1: 1$ \\
$\mathrm{InS}^{-\mathrm{d}}$ & $2: 1$ & $2: 1$ \\
\hline
\end{tabular}

${ }^{\mathrm{a} D a t a}$ from refs 9 and 10. DMACS ${ }^{-}$: 9,10-dimethoxyanthracene-2-sulfonate. ${ }^{\mathrm{b}}$ Data from ref 12. $\mathrm{ACS}^{-}$: anthracene-2-sulfonate. ${ }^{\mathrm{c}}$ Data from ref 11. $\mathrm{PyS}^{-}$: 1-pyrenesulfonate. ${ }^{\mathrm{d}}$ Data of this work. 

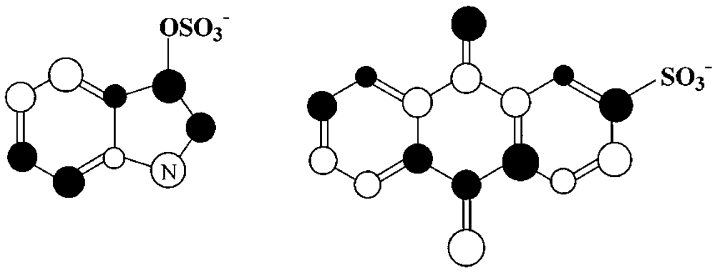

HOMO of InS

LUMO of 2-AQS

Figure 6. Top view of $\pi$ molecular orbitals of HOMO for $\mathrm{InS}^{-}$ and LUMO for 2-AQS ${ }^{-}$. Here an open circle $\bigcirc$ means a $2 \mathrm{pz}$ orbital perpendicular to the plane pf the paper with negative lobe above the plane; a solid circle means a $2 \mathrm{pz}$ orbital perpendicular to the plane pf the paper with positive lobe above the plane. In order to indicate the electron density, the radii of the circles are proportional to the coefficients of the atomic orbitals.

present polyion/CT complex system, it seems that dissociation rate of the CT complex is relatively fast due to the small of association constant for the CT complex. So, it seems that discussing the stationary structures of the CT complex is not significant. However, we investigated not general $\mathrm{CT}$ complexation but special one induced by the polyelectrolytes. By considering the above environment, it is significant to elucidate plausible structure of the CT complex around the polyion. The molecular orbital coefficients of HOMO for $\mathrm{InS}^{-}$ and those of LUMO for 2-AQS ${ }^{-}$were calculated and illustrated in Figure 6. By considering the overlap of electron orbitals between HOMO of $\mathrm{InS}^{-}$and LUMO of 2-AQS ${ }^{-}$, we tried to elucidate a plausible structure of the CT complex. A plausible structure of the 2:1type CT complex between $\mathrm{InS}^{-}$and 2-AQS ${ }^{-}$is shown in Figure 7. The most reasonable explanation for the formation of the 2:1-type CT complex in aqueous solutions of the polyelectrolytes is as follows. First, orbital overlapping between HOMO of $\mathrm{InS}^{-}$and LUMO of 2$\mathrm{AQS}^{-}$should be maximized in the CT complex structures, facing their charged groups $\left(-\mathrm{OSO}_{3}{ }^{-},-\mathrm{SO}_{3}{ }^{-}\right)$to the cationic charged sites of $\mathrm{PAAH}^{+}$and $\mathrm{PDPD}^{+}$. In this case, the aromatic parts can easily overlap with each other, which may cause the CT interaction effectively. Secondary, 2-AQS ${ }^{-}$has two $\mathrm{C}=\mathrm{O}$ parts, while $\mathrm{InS}^{-}$has only one $\mathrm{N}-\mathrm{H}$ part, which may facilitate the $\mathrm{CT}$ complexation between one 2-AQS ${ }^{-}$molecule and two $\mathrm{InS}^{-}$molecules. In the previous work, ${ }^{11}$ we carried out ultrafiltration method to estimate the extent of counterion binding to the polyion, and found that most of the aromatic counterions were bound to the polyion electrostatically. In other words, free counterions, which were not bound to the polyion, were hardly present in the polyelectrolyte solutions. From the results of the absorption and fluorescence spectroscopies, $2-\mathrm{AQS}^{-}$forms the dimmer between them in the vicinity of the polyion, whereas, $\mathrm{InS}^{-}$hardly forms the aggre-

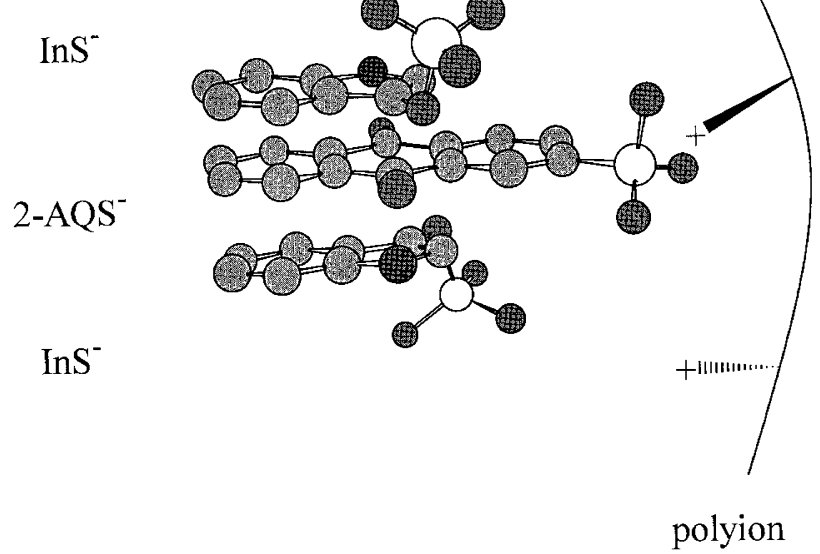

Figure 7. A plausible structure of a 2:1-type $\left(\operatorname{InS}^{-}: 2-\mathrm{AQS}^{-}\right)$ $\mathrm{CT}$ complex in the presence of the polyions.

gates. The $\mathrm{CT}$ interaction between $\mathrm{InS}^{-}$and $2-\mathrm{AQS}^{-}$ seems to be stronger than that between 2- $\mathrm{AQS}^{-}$'s. So, it seems that a 2:1-type CT complex may be conceivable to be a sandwich type complex but not an asymmetric one. $2-\mathrm{AQS}^{-}$forms an extremely stable dimer in aqueous solution in the presence of the polyions via dipole-dipole and/or dipole-induced dipole interactions due to mesomeric effect at the 9- and 10-position of anthraquinone ring $\left(\mathrm{C}^{\delta+}=\mathrm{O}^{\delta-}\right)^{21}$. However, when the $\mathrm{InS}^{-}$are present, a dipole moment of $\mathrm{InS}^{-}$on $\mathrm{N}-\mathrm{H}$ part $\left(\mathrm{N}^{\delta-}-\mathrm{H}^{\delta+}\right)$ of indoxyl ring, may interact with between $\mathrm{C}=\mathrm{O}$ part on $2-\mathrm{AQS}^{-}$and $\mathrm{N}-\mathrm{H}$ part on $\mathrm{InS}^{-}$. This interaction would interrupt the formation of $2-\mathrm{AQS}^{-}$dimer, and cause the formation of a sandwich-type CT complex. Because of the probability of InS-, which exists in the vicinity of the polyion, was high due to the counterion binding, more stable 2:1-type complex was preferentially formed even if a 1:1-type complex was transiently formed around the polyion. Once the precipitation of the polymer/CT complex or crystal of the CT complexes will be recovered from the solution, it may be possible to obtain more clear information about the CT interaction. We are now trying to obtain those precipitations for the further analysis.

As a conclusion, it is found that a novel 2:1- type CT complex was formed by using a heterocyclic compound as a counterion in polyelectrolyte solutions. This work indicates a possibility that new types of CT structures will be designed by devising the combination of donor, acceptor and the polyelectrolyte molecules. 


\section{REFERENCES}

1. H. A. Benesi and J. H. Hildebrand, J. Am. Chem. Soc., 71, 2703 (1949).

2. R. M. Keefer and L. J. Andrews, J. Am. Chem. Soc., 72, 4677 (1950).

3. H. Tsubomura, Bull. Chem. Soc. Jpn., 27, 1 (1954).

4. P. A. D. de Maine and J. Peone, Jr., J. Mol. Spectrosc., 4, 262 (1960).

5. W. R. Gilkerson and A. L. Mixon, J. Solution Chem., 19, 491 (1990).

6. F. Oosawa, "Polyelectrolytes", Marcel Dekker, New York, N.Y., 1971.

7. B. Boussouria, A. Ricard, and R. Audebert, J. Polym. Sci., Polym. Phys. Ed., 26, 649 (1988).

8. H. E. Rios, C. Camboa, and G. Ternero, J. Polym. Sci., Polym. Phys. Ed., 29, 805 (1991).

9. T. Itaya, Y. Kawabata, H. Ochiai, K. Ueda, and A. Imamura, Bull. Chem. Soc. Jpn., 67, 1538 (1994).

10. T. Itaya, Y. Kawabata, H. Ochiai, K. Ueda, and A. Imamura,
Bull. Chem. Soc. Jpn., 67, 2047 (1994).

11. Y. Kawabata, T. Itaya, Y. Sasaki, H. Ochiai, K. Ueda, and A. Imamura, Polym. J., 27, 542 (1995).

12. Y. Kawabata, T. Itaya, Y. Sasaki, H. Ochiai, K. Ueda, and A. Imamura, Bull. Chem. Soc. Jpn., 69, 2453 (1996).

13. Y. Kawabata, T. Itaya, Y. Sasaki, H. Ochiai, K. Ueda, and A. Imamura, Polym. J., 29, 211 (1997).

14. T. Itaya and H. Ochiai, J. Polym. Sci., Polym. Phys. Ed., 30, 587 (1992).

15. J. J. P. Stewart, "MOPAC Ver. 5.0: QCPE \# 455”, Frank J. Seiler Research Laboratory, U.S. Air Force Academy, Colorado Springs, Colorado 80840-6528, USA.

16. a) J. J. P. Stewart, J. Comput. Chem., 10, 209 (1989).

b) J. J. P. Stewart, J. Comput. Chem., 10, 221 (1989).

17. C. K. Prout and B. Mayah, J. Chem. Soc., Faraday Trans., 2, 68, 1072 (1972).

18. D. Job, Ann. Chim. Phys., 9, 113 (1928).

19. R. S. Mulliken, J. Am. Chem. Soc., 74, 811 (1952).

20. R. S. Mulliken, Rec. Trav. Chim., Pays-Bas., 75, 845 (1956).

21. T. Sato, T. Ogawa, and K. Kano, J. Phys. Chem., 88, 3678 (1984). 